\title{
Factors predictive of papillary thyroid micro-carcinoma with bilateral involvement and central lymph node metastasis: a retrospective study
}

Yi-Li Zhou, Er-li Gao, Wei Zhang, Han Yang, Gui-Long Guo, Xiao-Hua Zhang* and Ou-Chen Wang*

\begin{abstract}
Background: The optimal resection extent for papillary thyroid microcarcinoma (PTMC) remains controversial. The objective of the study was to investigate risk factors of bilateral PTMC and central lymph node metastasis (CLNM) to guide surgical strategies for PTMC patients.

Methods: We retrospectively reviewed 211 PTMC patients who underwent total thyroidectomy (TT) and 122 clinical lymph node-negative (CNO) cases that underwent prophylactic central lymph node dissection (CLND) between 2010 and 2011. The frequency, pattern, and predictive factors for bilateral PTMC and CLNM in these patients were studied using univariate and multivariate analysis with respect to the following variables: age, gender, extrathyroidal extension (ETE), T stage, with Hashimoto thyroiditis (HT), tumor size and multifocality based on final pathology, and preoperative evaluation using ultrasonography (US).

Results: Fifty-four of $211(25.6 \%)$ patients had bilateral PTMC. In multivariate analysis, multifocality $(P<0.001$, $\mathrm{OR}=23.900)$ and tumor size $\geq 7 \mathrm{~mm}(P=0.014, \mathrm{OR}=2.398)$ based on US were independent predictive factors for bilateral PTMC which was also independently associated with multifocality $(P<0.001, O R=29.657)$ and tumor size $\geq 7 \mathrm{~mm}(P=0.005, \mathrm{OR}=2.863)$ based on final pathology. Among $122 \mathrm{cNO}$ patients who underwent prophylactic CLND, we found $49.2 \%$ of patients had CLNM. CLNM was independently associated with men, age $<50$ years and tumor size $\geq 7 \mathrm{~mm}$ based on final pathology or preoperative US.

Conclusions: $\Pi$ should be considered for PTMC patients who are found multifocality and tumor size $\geq 7 \mathrm{~mm}$ based on preoperative US. CLND need be considered in cNO patients who are men, aged $<50$ years or tumor size $\geq 7 \mathrm{~mm}$ based on preoperative US.
\end{abstract}

Keywords: Papillary micro-carcinoma, Bilateral thyroid cancer, Multifocality, Thyroidectomy, Central lymph node metastasis

\section{Background}

Thyroid cancer is the most frequent endocrine malignancy, accounting for approximately $1 \%$ of all malignant tumors in the United States [1] and 5.90\% (with the incidence of $21.76 / 100,000$ ) in one district of Wenzhou (a coastal city in Southeast China, with a referral population of $7,558,000)$ [2]. Papillary thyroid carcinoma (PTC) represents the most common type, with incidence

\footnotetext{
*Correspondence: ZXH52011@gmail.com; woc0099@gmail.com Department of Oncology, The First Affiliated Hospital of Wenzhou Medical

College, No.2 Fuxue lane, Wenzhou, Zhejiang, China
}

increasing each year, especially in papillary thyroid microcarcinoma (PTMC) which is a type of PTC with a maximum diameter of $1.0 \mathrm{~cm}$ or less [3]. Unfortunately PTMC treatment is still controversial. While some doctors believe that the observation is appropriate, most advocate surgical resection [4,5]. In general, TT or therapeutic CLND should be performed when bilateral lobe involvement or CLNM is preoperatively detected. However, unilateral lobectomy may be applicable for patients who have only found PTMC confined to the unilateral lobe based on preoperative detection [6-8]. It 
had been reported that the rate of PTMC bilateral involvement was about $10-30 \%$ [9-11] and the rate of CLNM could reach up to $61 \%$ [12]. Whether TT or CLND should be offered to patients who could not detect bilateral lobe involvement or CLNM preoperatively is still controversial. So, how to predict PTMC with bilateral involvement or CLNM is crucial for determining initial surgical resection.

In this study, we retrospectively examined the incidence and related risk factors of PTMC with bilateral involvement and CLNM, attempting to reveal the independent predictors and hope to identify a subset of PTMC patients who may benefit from TT or CLND in initial surgery.

\section{Methods}

This study was approved by the institutional review board of the First Affiliated Hospital of Wenzhou Medical College. A total of 211 cases of PTMC patients were initially treated in our oncology department between 2010 and 2011. All patients had no history of neck irradiation and underwent preoperative US and US-guided fine needle aspiration biology (FNAB) whose diagnosis was PTC. TT was routinely operated and ultimately diagnosed as PTMC. Cases with accidental discovery of PTC and patients who underwent completion of total thyroidectomy were not found in our series. All patients accepted CLND routinely; apart from 89 patients whose preoperative detection of suspicious neck lymph nodes, 122 cases with cNO who underwent prophylactic CLND were included in the study of CLNM.

The following variables were used to analyze risk factors of PTMC bilateral involvement and CLNM: gender, age at diagnosis, final pathological primary tumor size and mulifocality, extrathyroidal extension (ETE), with Hashimoto thyroiditis (HT), primary tumor size and mulifocality based on preoperative US. Final pathological PTMC bilateral involvement and CLNM were examined as binary variables. All pathological findings were confirmed by two experienced endocrine pathologists and PTMC diagnosis was defined as PTC whose maximum size is $\leq 1 \mathrm{~cm}$ according to World Health Organization standards. Bilateral PTMC was diagnosed according to PTMC in both sides of the thyroid gland which differed from unilateral PTMC with foci in only one side lobe or isthmus. Mulifocality was defined as more than one tumor lesion in the primary tumor ipsilateral lobe. Tumor size in multifocal PTMC patients was measured according to maximum diameter of the primary tumor. Primary tumor size based on preoperative US was measured by the standard of change in echo edge. Preoperative mulifocality was defined as more than one suspicious lesion in one side lobe according to US findings. Suspicious lesions based on US expressed as irregular shape, ill-defined margin, echogenicity, micro-calcification, or vascularity.
The results are expressed as the mean $\pm \mathrm{SD}$. To compare the differences, two-tailed student $t$ test was used in measurement data and chi-square test or Fisher exact test was used in enumeration data, while Logistic regression multivariate analysis was used for further study. The application of two-tailed test $P$ value $<0.05$ was considered statistically significant. Statistical analysis was performed using SPSS 18.0.

\section{Results}

A total of 211 patients consisted of 179 women and 32 men with a median age of $49 \pm 11$ years (range, 23-79 years). The median size of the primary thyroid cancer was $5.8 \pm 2.7 \mathrm{~mm}(1-10 \mathrm{~mm})$. Mulifocality was found in 25 patients (11.8\%) and HT was found in 59 patients. ETE was found in 10 patients (4.7\%), in which seven cases were classified as T3 staging and three cases were classified as T4 staging (Table 1). Of the 211 patients with PTMC, $54(25.6 \%)$ had bilateral disease, and 157 (74.4\%) were unilateral PTMCs. Univariate analysis of potential clinicopathologic factors associated with bilateral PTMC is shown in Table 1. Contralateral PTMC was significantly more frequent in patients with final pathological multifocality $(P<0.001)$ and primary tumor size $\geq 5 \mathrm{~mm}$ or $\geq 7 \mathrm{~mm}(P=0.015,0.018$, respectively $)$.

Table 1 Clinicopathological characteristics and univariate analysis of 211 patients

\begin{tabular}{|c|c|c|c|c|}
\hline Characteristics & $\begin{array}{l}\text { Total } \\
(n=211)\end{array}$ & $\begin{array}{l}\text { Bilateral } \\
\text { PTMC }(n=54)\end{array}$ & $\begin{array}{l}\text { Unilateral } \\
\text { PTMC }(n=157)\end{array}$ & $P$ value \\
\hline Gender(M/F) & $32 / 179$ & $8 / 46$ & $24 / 133$ & 0.934 \\
\hline Age $\pm S D$ (years) & $49 \pm 11$ & $49 \pm 10$ & $48 \pm 11$ & $0.679^{a}$ \\
\hline$\geq 45 /<45$ & $143 / 68$ & $38 / 16$ & $105 / 52$ & 0.636 \\
\hline$\geq 50 /<50$ & $97 / 114$ & $23 / 31$ & $74 / 83$ & 0.564 \\
\hline $\begin{array}{l}\text { Primary } \\
\text { tumor size } \pm S D(\mathrm{~mm})\end{array}$ & $5.8 \pm 2.7$ & $6.8 \pm 2.6$ & $5.5 \pm 2.7$ & $0.001^{a, b}$ \\
\hline$\geq 5 /<5$ & $144 / 67$ & $44 / 10$ & $100 / 57$ & $0.015^{b}$ \\
\hline$\geq 7 /<7$ & $81 / 130$ & $28 / 26$ & $53 / 104$ & $0.018^{b}$ \\
\hline Multifocality (\%) & $25(11.8)$ & $21(38.9)$ & $4(2.6)$ & $<0.001^{b}$ \\
\hline ETE (\%) & $10(4.7)$ & $5(9.3)$ & $5(3.2)$ & $0.128^{c}$ \\
\hline T stage (T1/2:T3/4) & $201 / 10$ & $49 / 5$ & $152 / 5$ & $0.128^{c}$ \\
\hline With HT (\%) & $59(28.0)$ & $20(37.0)$ & $39(24.8)$ & 0.085 \\
\hline $\begin{array}{l}\text { Preoperative } \\
\text { tumor size }(\mathrm{mm})\end{array}$ & $6.1 \pm 2.9$ & $7.1 \pm 2.7$ & $5.8 \pm 2.8$ & $0.005^{a, b}$ \\
\hline$\geq 5 /<5$ & $152 / 59$ & $46 / 8$ & $106 / 51$ & $0.013^{b}$ \\
\hline$\geq 7 /<7$ & $85 / 126$ & $29 / 25$ & $56 / 101$ & $0.020^{b}$ \\
\hline $\begin{array}{l}\text { Preoperative } \\
\text { multifocality (\%) }\end{array}$ & 19 (8.6) & 16 (29.6) & $3(1.9)$ & $<0.001^{b, c}$ \\
\hline
\end{tabular}

${ }^{a}$ Calculated using two-tailed student $t$ test.

${ }^{b}$ Statistically significant $(P<0.05)$.

'Calculated using Fisher exact test, others calculated using chi-square test. ETE, extrathyroidal extension; HT,Hashimoto thyroiditis; PTMC, papillary thyroid microcarcinoma. 
There were no significant differences between the presence of contralateral carcinoma and age, gender, ETE, T stage and with HT. We also found the preoperative multifocality $(P<0.001)$ and tumor size $(\geq 5 \mathrm{~mm}$ or $\geq 7 \mathrm{~mm}$, $P=0.013,0.020$, respectively) which prompted by US were associated with bilateral PTMC.

We conducted multivariate logistic regression analysis of final pathological factors and preoperative factors separately. The results showed that tumor size $\geq 5 \mathrm{~mm}$ as the size threshold was not an independent factor, whose results of the analysis did not show. However, final pathological multifocality $(P<0.001, \mathrm{OR}=29.657)$ and primary tumor size $\geq 7 \mathrm{~mm}(P=0.005, \mathrm{OR}=2.869)$ still showed a significant correlation with bilateral PTMC. The same results were found in preoperative multifocality $(P<0.001)$ and primary tumor size $\geq 7 \mathrm{~mm}(P=0.014$, $\mathrm{OR}=2.398)$ which prompted by US. Table 2 shows the results of logistic regression analysis.

Of 122 cN0 patients who underwent CLND, 60 cases (49.2\%) had CLNM. Univariate analysis of relevant clinicopathologic factors in association with CLNM is expressed in Table 3. Apart from ETE, T stage and with HT, others as men $(P=0.015)$, aged $<50$ years $(P=0.011)$, final pathological tumor size $\geq 7 \mathrm{~mm} \quad(P=0.011)$, multifocality $(P=0.020)$, and bilateral PTMC $(P=0.020)$ were significantly related to CLNM. Similarly, preoperative tumor size $\geq 7 \mathrm{~mm}$ and multifocality which was promoted by US were also significant differences between the central lymph node positive and negative groups $(P=0.001$ and 0.027 , respectively).

However, further multivariate analysis showed that bilateral PTMC did not enter the final logistic regression equation $(P=0.367)$ and multifocality was also a confounding factor $(P=0.138)$. Interestingly, being male $(P=0.008, \mathrm{OR}=4.848)$, aged $<50$ years $(P=0.004, \mathrm{OR}=$ 3.442 ), and the final pathological tumor size $\geq 7 \mathrm{~mm}$ $(P=0.011, \quad$ OR $=2.908)$ were independently associated with CLNM. At the same time, logistic regression

Table 2 Logistic regression analysis of the significant risk factors in association with bilateral PTMC

\begin{tabular}{|c|c|c|c|c|c|}
\hline Factors & $\beta$ & S.E. & $P$ value & OR value & $95 \% \mathrm{Cl}$ \\
\hline \multicolumn{6}{|l|}{ Final pathological factors } \\
\hline $\begin{array}{l}\text { Tumor size } \\
(\geq 7 \mathrm{~mm} /<7 \mathrm{~mm})\end{array}$ & 1.054 & 0.378 & $0.005^{\mathrm{a}}$ & 2.869 & $1.366-6.023$ \\
\hline Multifocality & 3.390 & 0.601 & $<0.001^{\mathrm{a}}$ & 29.657 & $9.140-96.234$ \\
\hline Constant & -2.028 & 0.286 & & & \\
\hline \multicolumn{6}{|l|}{ Preoperative factors } \\
\hline $\begin{array}{l}\text { Preoperative tumor } \\
\text { size }(\geq 7 \mathrm{~mm} /<7 \mathrm{~mm})\end{array}$ & 0.875 & 0.357 & $0.014^{\mathrm{a}}$ & 2.398 & $1.192-4.824$ \\
\hline Preoperative multifocality & 3.174 & 0.668 & $<0.001^{\mathrm{a}}$ & 23.900 & $6.456-88.475$ \\
\hline Constant & -1.806 & 0.263 & & & \\
\hline
\end{tabular}

${ }^{a}$ Statistically significant $(P<0.05)$
Table 3 Clinicopathological characteristics and univariate analysis of 122 cases of PTMC patients who underwent prophylactic CLND

\begin{tabular}{|c|c|c|c|c|}
\hline Characteristics & $\begin{array}{l}\text { Total } \\
(n=122)\end{array}$ & $\begin{array}{l}\text { CLNM + } \\
(n=60)\end{array}$ & $\begin{array}{l}\text { CLNM - } \\
(n=62)\end{array}$ & $\begin{array}{l}P \\
\text { Value }\end{array}$ \\
\hline Gender (M/F) & $60 / 62$ & $44 / 16$ & $16 / 46$ & $0.015^{a}$ \\
\hline Age $\pm S D$ (years) & $48 \pm 11$ & $46 \pm 10$ & $50 \pm 11$ & $0.044^{a, b}$ \\
\hline$\geq 45 /<45$ & $83 / 39$ & $37 / 23$ & $46 / 16$ & 0.138 \\
\hline$\geq 50 /<50$ & $57 / 65$ & $21 / 39$ & $36 / 26$ & $0.011^{\mathrm{a}}$ \\
\hline Tumor size $\pm S D(\mathrm{~mm})$ & $6.5 \pm 2.6$ & $7.2 \pm 2.3$ & $5.8 \pm 2.7$ & $0.002^{a, b}$ \\
\hline$\geq 5 /<5$ & $95 / 27$ & $51 / 9$ & $44 / 18$ & 0.062 \\
\hline$\geq 7 /<7$ & $59 / 63$ & $36 / 24$ & $23 / 39$ & $0.011^{a}$ \\
\hline Multifocality (\%) & 19 (15.6) & $14(23.3)$ & $5(8.1)$ & $0.020^{a}$ \\
\hline ETE (\%) & $7(5.7)$ & $5(8.3)$ & $2(3.2)$ & $0.269^{c}$ \\
\hline T stage (T1/2:T3/4) & $115 / 7$ & $55 / 5$ & $60 / 2$ & $0.269^{c}$ \\
\hline With HT (\%) & $43(35.2)$ & $19(31.7)$ & $24(38.7)$ & 0.416 \\
\hline Bilateral PTMC (\%) & $60(50.8)$ & $26(61.9)$ & $34(42.5)$ & $0.042^{a}$ \\
\hline $\begin{array}{l}\text { Preoperative tumor } \\
\text { size }(\mathrm{mm})\end{array}$ & $6.8 \pm 2.8$ & $7.5 \pm 2.6$ & $6.1 \pm 2.9$ & $0.008^{a}$ \\
\hline$\geq 5 /<5$ & $99 / 23$ & $52 / 8$ & $47 / 15$ & 0.125 \\
\hline$\geq 7 /<7$ & $61 / 61$ & $37 / 23$ & $24 / 38$ & $0.001^{\mathrm{a}}$ \\
\hline Preoperative multifocality (\%) & 16(13.1) & $12(20.0)$ & $4(6.6)$ & $0.027^{a}$ \\
\hline
\end{tabular}

a Statistically significant $(P<0.05)$.

${ }^{b}$ Calculated using two-tailed student $t$ test

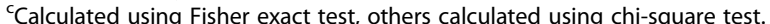
CLNM, central lymph node metastasis; ETE, extrathyroidal extension; HT, Hashimoto thyroiditis; PTMC, papillary thyroid microcarcinoma.

analysis of preoperative factors also reached a similar result: males $(P=0.008, \quad O R=4.910)$, aged $<50$ years $(P=0.005, \mathrm{OR}=3.311)$ and the preoperative tumor size $\geq$ $7 \mathrm{~mm}(P=0.009$, OR $=2.964)$ based on US were independent predictors of CLNM. Table 4 shows results of logistic regression analysis using the significant risk factors in association with CLNM.

\section{Discussion}

PTMC will likely draw continued attention given its increasing incidence in recent years. Although TT and CLND currently constitute the common initial surgical management of patients with larger PTC, the best surgical extent for PTMC is still a controversial topic [13]. When surgery is performed for PTMC, it is generally accepted that TT or CLND should be performed for preoperatively detected bilateral PTMC or CLNM. However, the optimal extent of surgical resection in cases with preoperatively undetected bilateral PTMC or CLNM remains a topic of debate. We retrospectively reviewed clinicopathological factors of PTMC patients and found that primary tumor $\geq 7 \mathrm{~mm}$ and multifocality were independent predictors of bilateral PTMC, and being male, aged $<50$ years, and primary tumor $\geq 7 \mathrm{~mm}$ could be used to predict CLNM. Further, multifocality and primary tumor $\geq 7 \mathrm{~mm}$ could be 
Table 4 Logistic regression analysis of the significant risk factors in association with CLNM

\begin{tabular}{|c|c|c|c|c|c|}
\hline Factors & $\beta$ & S.E. & $P$ value & OR value & $95 \% \mathrm{Cl}$ \\
\hline \multicolumn{6}{|l|}{ Final pathological factors } \\
\hline Gender (M/F) & 1.578 & 0.592 & $0.008^{a}$ & 4.848 & $1.519-15.466$ \\
\hline Age $(<50 y / \geq 50 y)$ & 1.236 & 0.428 & $0.004^{\mathrm{a}}$ & 3.442 & $1.488-7.963$ \\
\hline $\begin{array}{l}\text { Tumor size } \\
(\geq 7 \mathrm{~mm} /<7 \mathrm{~mm})\end{array}$ & 1.067 & 0.419 & $0.011^{\mathrm{a}}$ & 2.908 & $1.278-6.614$ \\
\hline Multifocality & 0.991 & 0.667 & 0.138 & 2.693 & $0.728-9.956$ \\
\hline Bilateral PTMC & 0.436 & 0.484 & 0.367 & 1.547 & $0.600-3.993$ \\
\hline Constant & -1.787 & 0.448 & & & \\
\hline \multicolumn{6}{|l|}{ Preoperative factors } \\
\hline Gender (M/F) & 1.591 & 0.596 & $0.008^{\mathrm{a}}$ & 4.910 & $1.526-15.796$ \\
\hline Age (<50y/ $\geq 50 y)$ & 1.199 & 0.424 & $0.005^{\mathrm{a}}$ & 3.311 & $1.443-7.634$ \\
\hline $\begin{array}{l}\text { Preoperative tumor size } \\
(\geq 7 \mathrm{~mm} /<7 \mathrm{~mm})\end{array}$ & 1.086 & 0.418 & $0.009^{\mathrm{a}}$ & 2.964 & $1.305-6.729$ \\
\hline Preoperative multifocality & 0.806 & 0.706 & 0.253 & 2.240 & $0.562-8.931$ \\
\hline Bilateral PTMC & 0.584 & 0.466 & 0.210 & 1.793 & $0.719-4.469$ \\
\hline Constant & -0.600 & 0.371 & & & \\
\hline
\end{tabular}

${ }^{\mathrm{a}}$ Statistically significant $(P<0.05)$.

prompted by preoperative US to identify PTMC patients who need TT or CLNM.

Surgeons who advocated TT believed that thyroid cancer often presented in both sides of thyroid lobes. Then, how many cases had bilateral involvement in thyroid cancer patients? Studies had reported that the rate of bilateral PTC ranged from $13 \%$ to $56 \%$ that could be found in completion thyroidectomy and TT [14-17] and incidence of bilateral PTMC was approximately $10-30 \%$ in PTMC patients $[9-11,17,18]$. In our study, $25.6 \%$ of PTMC patients who underwent TT had contralateral PTMC. This rate was consistent with the previous reports $[9-11,17,18]$. In our opinion, a $25.6 \%$ ratio for a contralateral carcinoma does not justify routine TT for all PTMC patients. Multifocality had been prompted as a predictor of contralateral thyroid cancer in a number of studies $[14,15,19,20]$. Our study confirmed the predictive value of multifocality and found that $84 \%$ of multifocal PTMC patients had contralateral lobe foci, which may be due to that bilateral PTMC often arise from a single clone and intrathyroidal metastasis [21]. Primary tumor size in the previous study was considered to be nothing to do with the contralateral PTC $[15,20,22-24]$. However, our study found that bilateral PTMC may be more vulnerable to have a large primary tumor $(\geq 5 \mathrm{~mm} / \geq 7 \mathrm{~mm}$ ), and primary tumor $\geq 7 \mathrm{~mm}$ was an independent predictor of contralateral lobe PTMC. A reason inconsistent results may be attributed to our research was a retrospective study and the object was PTMC patents who underwent TT, compared to the previous prospective study [22] and patients with clinical unilateral PTMC [20]. Moreover, the number of PTMC cases in our study increased compared to the study of Pitt et al. [15] and we firstly used a tumor size $>7 \mathrm{~mm}$ as the size threshold in study of bilateral PTMC. In addition, previous studies had reported that bilateral PTC was inter-related with advanced T stage and high incidence of ETE [16,23]. However, we did not obtain the same results in PTMC cases agreed with previous studies of bilateral PTMC [20,22]. The reasons may be attributed to that PTMC was found early and micro-foci, which may not yet demonstrate full biological behavior. Others such as gender, age, and with HT were not found significant difference as other papers reported [20,22,24].

Therapeutic CLND in PTMC patients is always necessary, whereas prophylactic CLND remains a subject of considerable debate. The 2009 guidelines of the American Thyroid Association (ATA) recommend prophylactic CLND in patients with cNO PTCs, particularly in those with advanced T3 and T4 primary tumors, but do not recommend elective central neck dissection in patients with small, non-invasive cNO PTCs [25]. A high incidence of CLNM in PTMC patients has been reported (up to 61\%) [12]. Our study found the CLNM rate was 49.2\% in PTMC patients with preoperatively undetected CLNM. Although US has been regarded as a sensitive imaging modality for thyroid screening and diagnosis, US has a low sensitivity in evaluation of metastasis in CLNM [26]. Similarly, in our study, imaging studies were not useful in the detection of CLNM. Age is known to be an important prognostic factor for patients with PTC greater than $1 \mathrm{~cm}$; however, its prognostic value in PTMC was uncertain [12,27-29]. Most studies used an age $<45$ years as the age threshold [30,31]. In our study, age $<50$ years was found to be independently associated with the greatest risk of CLNM, but an age $<45$ years as the age threshold may be too small to assess the CLNM. In addition, consistent with previous reports, we also found that being male was an independent risk factor of CLNM. Previous studies have suggested that CLNM was associated with tumor size [12,32,33]. Most studies used a tumor size $>5 \mathrm{~mm}$ as the size threshold. Lee et al. thought that a cutoff value of $7 \mathrm{~mm}$ may be considered the threshold of aggressiveness of PTMCs [34]. Our analysis found that tumor size $\geq 7 \mathrm{~mm}$ was independently associated with CLNM, but a threshold $>5 \mathrm{~mm}$ may be too small to assess the CLNM. We also revealed preoperative tumor size $\geq 7 \mathrm{~mm}$ based on US could be used to predict CLNM. Thus, preoperative tumor size $\geq 7 \mathrm{~mm}$ based on US, combined with being male and aged $<50$ years can be used to predict the CLNM, and guide CLND. In our study, we found that cases who had bilateral PTMC and multifocality may be prone to CLNM $(P=0.042$ and 0.020 , respectively), but they were not independent risk factors. In addition, disagreeing with a previous report [28], our study did not prompt that 
CLNM was associated with ETE and T stage. The reason may be due to our low rate of ETE which was not included microscopic extension.

Although our analysis is limited because of the lack of both long-term follow-up results and prognostic implication of bilateral PTMC and CLNM, we did highlight the predictive value of preoperative primary tumors $\geq 7 \mathrm{~mm}$ and multifocality both prompted by US, which can be contributed to compensate for the lack of preoperative sensitivity to reveal undetected bilateral PTMC and CLNM.

\section{Conclusions}

Of all PTMC patients who underwent TT, 25.6\% had bilateral PTMC. Tumor size $\geq 7 \mathrm{~mm}$ and at least one multifocal lobe were independent risk factors for bilateral PTMC and both can be prompted by US to guide TT. The rate of CLNM was $49.1 \%$ in cN0 patients. Factors such as tumor foci $\geq 7 \mathrm{~mm}$ based on final pathology or US, being male, and a younger age ( $<50$ years) can be used to predict CLN metastasis. Surgeons are justified to offer TT to PTMC patients with multifocality and foci $\geq 7 \mathrm{~mm}$ based on preoperative US. CLND needs to be considered in PTMC patients who are men, aged $<50$ years, or foci $\geq 7 \mathrm{~mm}$ based on preoperative US.

\section{Competing interests}

The author(s) declare that they have no competing interest.

\section{Acknowledgements}

This work was supported by the National 863 project of China (No.2012AA020315) and Zhejiang Provincial Natural Science Foundation (Y207526) in China.

\section{Authors' contributions}

YLZ substantially contributed to the conception and design, acquisition of data, drafting and revision of the article. ELG and WZ participated in the data collection and revisions; HY and GLG substantially contributed to analysis and interpretation of data, revision of the article. XHZ and OCW acted as corresponding authors and did the conception and revisions. All authors read and approved the final manuscript.

Received: 1 February 2012 Accepted: 27 March 2012

Published: 27 April 2012

\section{References}

1. Sherman SI: Thyroid carcinoma. Lancet 2003, 361:501-511.

2. Zheng W, Zhang Z: An analysis of cancer incidence in 2005 in Lucheng District, Wenzhou City, Zhejiang Province. Bull Chin Cancer 2007, 16:306-308.

3. Davies L, Welch HG: Increasing incidence of thyroid cancer in the United States, 1973-2002. JAMA 2006, 295:2164-2167.

4. Shindo M, Wu JC, Park EE, Tanzella F: The importance of central compartment elective lymph node excision in the staging and treatment of papillary thyroid cancer. Arch Otolaryngol Head Neck Surg 2006, 132:650-654.

5. Ito Y, Uruno T, Nakano K, Takamura Y, Miya A, Kobayashi K, Yokozawa T, Matsuzuka F, Kuma S, Kuma K, Miyauchi A: An observation trial without surgical treatment in patients with papillary microcarcinoma of the thyroid. Thyroid 2003, 13:381-387.

6. Baudin E, Travagli JP, Ropers J, Mancusi F, Bruno-Bossio G, Caillou B, Cailleux AF, Lumbroso JD, Parmentier C, Schlumberger M: Microcarcinoma of the thyroid gland: the Gustave-Roussy Institute experience. Cancer 1998, 83:553-559.
7. Noguchi S, Yamashita H, Murakami N, Nakayama I, Toda M, Kawamoto H: Small carcinomas of the thyroid. A long-term follow-up of 867 patients. Arch Surg 1996, 131:187-191.

8. Hay ID, Grant CS, Taylor WF, McConahey WM: Ipsilateral lobectomy versus bilateral lobar resection in papillary thyroid carcinoma: a retrospective analysis of surgical outcome using a novel prognostic scoring system. Surgery 1987, 102:1088-1095.

9. Hay ID, Hutchinson ME, Gonzalez-Losada T, Mclver B, Reinalda ME, Grant CS, Thompson GB, Sebo TJ, Goellner JR: Papillary thyroid microcarcinoma: a study of 900 cases observed in a 60-year period. Surgery 2008, 144:980-987. discussion 987-988.

10. Mercante G, Frasoldati A, Pedroni C, Formisano D, Renna L, Piana S, Gardini G, Valcavi R, Barbieri V: Prognostic factors affecting neck lymph node recurrence and distant metastasis in papillary microcarcinoma of the thyroid: results of a study in 445 patients. Thyroid 2009, 19:707-716.

11. Jacquot-Laperriere S, Timoshenko AP, Dumollard JM, Peoc'h M, Estour B, Martin C, Prades JM: Papillary thyroid microcarcinoma: incidence and prognostic factors. Eur Arch Otorhinolaryngol 2007, 264:935-939.

12. Wada N, Duh QY, Sugino K, Iwasaki H, Kameyama K, Mimura T, Ito K, Takami H, Takanashi Y: Lymph node metastasis from 259 papillary thyroid microcarcinomas: frequency, pattern of occurrence and recurrence, and optimal strategy for neck dissection. Ann Surg 2003, 237:399-407.

13. Cooper DS, Doherty GM, Haugen BR, Kloos RT, Lee SL, Mandel SJ, Mazzaferri EL, Mclver B, Sherman SI, Tuttle RM: Management guidelines for patients with thyroid nodules and differentiated thyroid cancer. Thyroid 2006, 16:109-142.

14. Pasieka JL, Thompson NW, McLeod MK, Burney RE, Macha M: The incidence of bilateral well-differentiated thyroid cancer found at completion thyroidectomy. World J Surg 1992, 16:711-716. discussion 716-717.

15. Pitt SC, Sippel RS, Chen H: Contralateral papillary thyroid cancer: does size matter? Am J Surg 2009, 197:342-347.

16. Wang W, Zhao W, Wang H, Teng X, Chen X, Li Z, Yu X, Fahey TJ 3rd, Teng L: Poorer prognosis and higher prevalence of BRAF (V600E) mutation in synchronous bilateral papillary thyroid carcinoma. Ann Surg Oncol 2012, 19:31-36.

17. Schonberger J, Marienhagen J, Agha A, Rozeboom S, Bachmeier E, Schlitt H, Eilles C: Papillary microcarcinoma and papillary cancer of the thyroid $<$ or $=1 \mathrm{~cm}$ : modified definition of the WHO and the therapeutic dilemma. Nuklearmedizin 2007, 46:115-120. quiz N141-112

18. Chow SM, Law SC, Chan JK, Au SK, Yau S, Lau WH: Papillary microcarcinoma of the thyroid-Prognostic significance of lymph node metastasis and multifocality. Cancer 2003, 98:31-40.

19. Kim ES, Kim TY, Koh JM, Kim Yl, Hong SJ, Kim WB, Shong YK: Completion thyroidectomy in patients with thyroid cancer who initially underwent unilateral operation. Clin Endocrinol (Oxf) 2004, 61:145-148.

20. Koo BS, Lim HS, Lim YC, Yoon YH, Kim YM, Park YH, Rha KS: Occult contralateral carcinoma in patients with unilateral papillary thyroid microcarcinoma. Ann Surg Oncol 2010, 17:1101-1105.

21. Wang W, Wang H, Teng X, Mao C, Teng R, Zhao W, Cao J, Fahey TJ 3rd, Teng L: Clonal analysis of bilateral, recurrent, and metastatic papillary thyroid carcinomas. Hum Pathol 2010, 41:1299-1309.

22. Connor MP, Wells D, Schmalbach CE: Variables predictive of bilateral occult papillary microcarcinoma following total thyroidectomy. Otolaryngol Head Neck Surg 2011, 144:210-215.

23. Hwang E, Pakdaman MN, Tamilia M, Hier MP, Black MJ, Rochon L, Payne RJ: Bilateral papillary thyroid cancer and associated histopathologic findings. J Otolaryngol Head Neck Surg 2010, 39:284-287.

24. Hwang E, Pakdaman MN, Black MJ, Payne RJ: Tumour size and bilateral thyroid cancer after thyroidectomy. Otolaryngol Head Neck Surg 2008, 139:P47.

25. Cooper DS, Doherty GM, Haugen BR, Kloos RT, Lee SL, Mandel SJ, Mazzaferri EL, Mclver B, Pacini F, Schlumberger M, Sherman SI, Steward DL, Tuttle RM: Revised American thyroid association management guidelines for patients with thyroid nodules and differentiated thyroid cancer. Thyroid 2009, 19:1167-1214.

26. Choi JS, Kim J, Kwak JY, Kim MJ, Chang HS, Kim EK: Preoperative staging of papillary thyroid carcinoma: comparison of ultrasound imaging and CT. AJR Am J Roentgenol 2009, 193:871-878.

27. Kwak JY, Kim EK, Kim MJ, Son EJ, Chung WY, Park CS, Nam KH: Papillary microcarcinoma of the thyroid: predicting factors of lateral neck node metastasis. Ann Surg Oncol 2009, 16:1348-1355. 
28. So YK, Son YI, Hong SD, Seo MY, Baek CH, Jeong HS, Chung MK: Subclinical lymph node metastasis in papillary thyroid microcarcinoma: a study of 551 resections. Surgery 2010, 148:526-531.

29. Roh JL, Kim JM, Park Cl: Central cervical nodal metastasis from papillary thyroid microcarcinoma: pattern and factors predictive of nodal metastasis. Ann Surg Oncol 2008, 15:2482-2486.

30. Lin JD, Chen ST, Chao TC, Hsueh C, Weng HF: Diagnosis and therapeutic strategy for papillary thyroid microcarcinoma. Arch Surg 2005, 140:940-945.

31. Ji QH, Zhang L, Zhu YX, Huang CP: Long-term impact of initial surgical and medical therapy on young patients with papillary thyroid cancer and bilateral cervical metastases. Chin Med J (Engl) 2008, 121:63-66.

32. Lee SH, Lee SS, Jin SM, Kim JH, Rho YS: Predictive factors for central compartment lymph node metastasis in thyroid papillary microcarcinoma. Laryngoscope 2008, 118:659-662.

33. Roti E, Rossi R, Trasforini G, Bertelli F, Ambrosio MR, Busutti L, Pearce EN, Braverman LE, Degli Uberti EC: Clinical and histological characteristics of papillary thyroid microcarcinoma: results of a retrospective study in 243 patients. J Clin Endocrinol Metab 2006, 91:2171-2178.

34. Lee KJ, Cho YJ, Kim SJ, Lee SC, Kim JG, Ahn CJ, Lee DH: Analysis of the clinicopathologic features of papillary thyroid microcarcinoma based on 7-mm tumor size. World J Surg 2011, 35:318-323.

doi:10.1186/1477-7819-10-67

Cite this article as: Zhou et al:: Factors predictive of papillary thyroid micro-carcinoma with bilateral involvement and central lymph node metastasis: a retrospective study. World Journal of Surgical Oncology 2012, 10:67.

\section{Submit your next manuscript to BioMed Central and take full advantage of:}

- Convenient online submission

- Thorough peer review

- No space constraints or color figure charges

- Immediate publication on acceptance

- Inclusion in PubMed, CAS, Scopus and Google Scholar

- Research which is freely available for redistribution 